\title{
A Hybrid Fire Warning Model Based on Cellular Automata
}

\author{
Jiayang Lin ${ }^{*}$, Qiang Fan, Jie Lu, Yuhui Peng and Wencheng Sun \\ Southwest Branch of State Grid Corporation of China, Chengdu, Sichuan Province, China.
}

\begin{abstract}
The rapid development of cities and the increasing complexity of its internal structure have led to pressing fire security problems, which calls for an effective and accurate comprehensive fire warning model. Most existing fire warning models predict only for a single fire scenario and can hardly balance the speed and accuracy in their predictions, which are not suitable for large-scale scenarios with complex structures. This paper proposes a fire warning model that includes both forest and building area based on Cellular Automata. Experimental areas were established to simulate fire warning according to the proposed hybrid model. The experimental results have shown that the model can quickly and accurately simulate the fire spread process and provide effective support for emergency decision-making in complex scenarios.
\end{abstract}

\section{Introduction}

With the rapid process of urbanization in China, there has been a marked growth of fire accidents. They not only cause incalculable loss of life and property, but also severely damage the natural ecological resources and break the balance of ecosystem [1]. In December 2017, a forest fire broke out in Ventura County, California, USA. Due to Hurricane Santa Ana, the fire spread out of control, burning an area of more than 59,800 hectares. More than 800 buildings were burned down and nearly 200,000 local residents were relocated [2]. So far, domestic and foreign scholars have conducted a lot of scientific studies on the process of fire spread and proposed many scientific and effective fire models. According to the fire spread regularity, the existing fire models can be classified as forest fire models and urban fire models. However, it is difficult to simulate complex fire scenarios, such as urban fires containing both forests and buildings, which include different types of combustible materials with different burning patterns. None of the existing fire models can satisfy the needs of fire warning in mixed scenarios. Therefore, it is urgent and necessary to simulate the fire spread in complex areas.

In this paper, we propose a fire warning model in mixed scenarios based on Cellular Automata to achieve accurate simulation of fire spread in complex areas containing both forests and buildings. Being real-time and low-cost, this model can provide a more realistic simulation and analysis of the fire spread process. It would provide effective support for the department of emergency management in fire plans and evacuation strategy and improve

*Corresponding author: 137833873@qq.com 
the quick response ability of the government. It would also reduce the maintenance cost of the fire emergency system, the loss of life and property and the destruction of natural ecology.

\section{Methodology}

Fire models are used to simulate the dynamic process of fire spread from the earliest fire spot to the surrounding areas over a period of time, which can predict the state of fire spread in real time and thus provide decision support for fire emergency rescue. The current researches mainly focused on two regular types of fires, forest fires and urban fires. Forest fire models are primarily targeted at burning trees in large-scale forests while urban fire models are mainly targeted at single burning buildings in urban areas. Meanwhile, heterogeneous forest-urban fire models were also studied to analyze the mechanism of fire spread between forest and urban areas. For the same type of fire models, different scholars analyzed the regularities of fires from different perspectives and proposed various types of fire models, such as empirical models based on historical fire statistics and experimental fire combustion, physical models based on purely physical heat of combustion theory, probabilistic models based on mathematical simulations and Cellular Automata models.

\subsection{Forest fire model}

For forest fire models, the most commonly used one in China is the empirical fire model proposed by scholars such as Zhengfei Wang and Xianmin Mao [2-3]. It has deduced a set of empirical mathematical formulas mainly based on the historical fire statistics of the Daxing'anling area of Heilongjiang Province and the experimental data of indoor fire combustion.

First, the initial velocity R0 of forest fire spread in $\mathrm{m} / \mathrm{min}$ is calculated based on the indoor combustion method, taking into consideration the influences of such environmental parameters as temperature, humidity and wind speed. The empirical formula is as follows:

$$
R_{0}=a^{*} T+b^{*} V+c * H-D
$$

Where $\mathrm{T}$ denotes air temperature ${ }^{\circ} \mathrm{C} ; \mathrm{V}$ denotes average wind scale in noon; $\mathrm{H}$ denotes minimum humidity value; $\mathrm{a}, \mathrm{b}, \mathrm{c}$ and $\mathrm{D}$ are empirical coefficients, generally taking the values of: $\mathrm{a}=0.03, \mathrm{~b}=0.05, \mathrm{c}=0.01, \mathrm{D}=0.3$.

After the spread rate of forest fire is calculated, we use a continuous extended polygon to simulate the dynamic process of fire spread based on Huygens principle [4]. First, starting from the coordinates of the fire site, we calculate the speed of forest fire spread in eight directions (north, northeast, east, southeast, south, southwest, west, and northwest) based on the empirical formula. Next, we calculate the distance of the forest fire spread in each direction based on the time interval of the dynamic forest fire spread. After updating the coordinate points in eight directions according to the distance obtained, we can get the fire spread polygon at each moment through point interpolation and fitting, so the fire spread range over time can be gained for fire warning.

\subsection{Urban fire model}

As for urban fires, most scholars currently construct physical models of urban fires based on physical thermal models, which analyze the state of each combustible from physical heat radiation and thermal convection. Due to the large number of input parameters and the huge 
consumption of computational resources, most of these physical models only model and analyze the combustion of a single building.

In the physical fire model, all combustibles have a life cycle, from the sleep and unignited stage, to the gradual combustion stage, then to the complete combustion stage, and finally to the decay stage until all combustibles burned out. In the four different stages of combustion, combustibles release different heat. In the sleep stage, as the combustibles are not ignited, no heat is released, but the maximum amount of heat is released when combustibles enter the full combustion stage, during which burning combustibles are most likely to ignite other unignited combustibles. However, if the volume of combustibles is too small, there will be no complete combustion stage even when all the combustibles have been completely burned. Accordingly, we calculate the time node value of each stage based on the physical model of urban buildings.

\subsection{Hybrid fire model}

Hybrid fire models are mainly to study the fire spread models at the convergence area of towns and forests, since the accelerated urbanization has resulted in closer distance between people's residence and natural forests and has caused increasing risk of mixed fires. In this paper, many fire models based on Cellular Automata are proposed to simulate the fire spread process. The hybrid fire models primarily aim at four types of fire spread: forest-toforest, forest-to-building, building-to-building, and building-to-forest. This paper elaborates a hybrid fire model based on object-oriented cellular automata.

In the Cellular Automata model, each cellular object has its specific and independent state properties. The states of building-to-building fire spread are mainly divided into the unignited state, the ignited state, the flash state, the fully combusted state, the crash state and the collapse state, which are represented by $0-5$ respectively.

When a building is on fire, the state of the building switches from unignited to ignited, and within a certain time interval, it may switch to other burning states. Only when the building is in the fully combusted or crash state, can the fire spread to the surrounding unignited buildings. We use ellipse model to demonstrate the fire-affected range and the shape is determined by the wind speed. Different wind speed produces different elliptical parameters.

After calculating the area of fire-affected ellipse, we figure out whether there are unignited buildings in the area affected by the burning building. If it exists, the probability of the building being ignited SFij is calculated as shown in the equation

$$
\mathrm{SF}_{\mathrm{ij}}=\mathrm{P}\left(\mathrm{B}_{\mathrm{j}}\right) * \mathrm{P}\left(\mathrm{D}_{\mathrm{j}}\right) * \mathrm{P}(\mathrm{W}) * \mathrm{P}\left(\mathrm{d}_{\mathrm{ij}}\right) * \mathrm{P}\left(\mathrm{S}_{\mathrm{i}}\right)
$$

Where $\mathrm{Bj}$ is the structure of the $\mathrm{jth}$ building; $\mathrm{P}(\mathrm{Bj})$ is the ignition capacity of buildings of different structures; $\mathrm{Dj}$ is the damage parameter of the jth building; $\mathrm{P}(\mathrm{Dj})$ is the ignition capacity of buildings in different degrees of damage; $\mathrm{P}(\mathrm{W})$ is the environmental elements; dij is the shortest distance between buildings, $\mathrm{P}(\mathrm{dij})$ is the distance influence; $\mathrm{Si}$ is the state parameter of the burning building $\mathrm{i} ; \mathrm{P}(\mathrm{Si})$ is the combustion state elements. The values of each parameter are shown in Table 1 
Table 1. Values of ignition probability parameters

\begin{tabular}{|c|c|c|c|c|c|c|c|}
\hline \multicolumn{2}{|c|}{$\begin{array}{c}\text { Building Structure } \\
\qquad P\left(B_{j}\right)\end{array}$} & \multicolumn{2}{|c|}{$\begin{array}{l}\text { Building Damage } \\
\qquad P\left(D_{j}\right)\end{array}$} & \multicolumn{2}{|c|}{$\begin{array}{c}\text { Environment } \\
P(W)\end{array}$} & \multicolumn{2}{|c|}{$\begin{array}{c}\text { Combustion State } \\
P\left(S_{i}\right)\end{array}$} \\
\hline $\begin{array}{l}\text { Wooden } \\
\text { Structure }\end{array}$ & 1.0 & $\begin{array}{c}\text { Severe } \\
\text { Damage }\end{array}$ & 0.6 & Disadvantage & 1.0 & $\begin{array}{c}\{0\},\{1\},\{2\}, \\
\{5\}\end{array}$ & 0 \\
\hline $\begin{array}{c}\text { Semi- } \\
\text { fireproof } \\
\text { materials }\end{array}$ & 0.8 & $\begin{array}{l}\text { Moderate } \\
\text { Damage }\end{array}$ & 1.0 & Average & 0.8 & $\{3\}$ & 0.4 \\
\hline $\begin{array}{l}\text { Fireproof } \\
\text { materials }\end{array}$ & 0.6 & $\begin{array}{c}\text { No } \\
\text { Damage }\end{array}$ & 0.9 & Advantage & 0.4 & $\{4\}$ & 1.0 \\
\hline
\end{tabular}

Where, $\mathrm{P}(\mathrm{dij})$ is the distance. The closer the building is to the burning building, the larger $\mathrm{P}(\mathrm{dij})$ is, as shown in the equation

$$
P\left(d_{i j}\right)=1-\frac{d_{i j}}{d_{i B}}
$$

Where diB represents the distance between building $\mathrm{i}$ and the intersection point of the ellipse of the fire-affected areas along direction dij. When the ignition probability SFij of building $\mathrm{j}$ is calculated, it is then compared with a uniformly distributed random number $\varepsilon$ in the range of $[0,1]$. If $S F i j>\varepsilon$, then building $\mathrm{j}$ will be ignited, otherwise, it will not.

The forest-to-building fire spread is relatively similar to the building-to-forest fire spread, and the vector superposition method can be used to determine whether there are changes in the burning medium. For the forest-to-building fire spread, the forest fire spread influence polygon is overlaid with the building vector layer to determine whether there is an overlapping area. If there is, the ignition probability of the building in the overlapping area will be judged using the Cellular Automata model. As for the building-to-forest fire spread, the range of the fire-affected ellipse of the burning building will be calculated and then overlaid with the forest vector layer. If the overlapping area exists, the nearest point from the overlapping area to the burning building is calculated and then taken as the starting point of the forest fire.

\section{Results and discussion}

\subsection{Experimental data}

The fire simulation system is mainly an integration of the fire model module, the data standard module and the 3D fire simulation module, which is used to demonstrate the application of the mixed fire model in the actual demonstration area, so as to verify the accuracy and real-time performance of the model. The basic data of the integrated system is used to support the $3 \mathrm{D}$ visualization in the $3 \mathrm{D}$ fire simulation module and to build a virtual 3D geographical scene, including DEM elevation data, remote sensing image data and 3D static model data.

The DEM elevation data used in this paper comes from the data of the 30-meter resolution terrain product of SRTM, and the DOM data, with a spatial resolution of 0.4 meters, comes from the high-resolution remote sensing satellite images of Google Earth. They provide data support for further analysis and understanding of the fire spread simulation in the later stage. 


\subsection{Experimental results}

In order to verify the robustness of the integrated fire simulation system, the paper conduct groups of comparative experiments by modifying the core parameters of the fire model, including wind speed, wind direction, temperature and natural fire-resistant elements. Also, in order to vividly explain the situation, we compare the effects of changes in parameters on simulation results of the fire model in two-dimensional scenarios with the same experimental duration, 30 minutes. The experiments have been conducted by $\mathrm{C} \#$ in Visual Studio 2010 and based on the package of Cesium.js.

The effect of wind direction on fire spread is firstly analyzed. The wind direction is set to east and north wind respectively with other parameters being the same and the time step being 10 minutes. The results are shown in Figure 1. It can be seen that when the wind direction is different, the main direction of fire spread is different, and the area of burning is also different. The area affected by fire increases with time, but the area of burning in different wind directions at each time step is nearly the same.

Wind speed is a major factor affecting the spread of fire. The experiment sets two wind speed parameters, namely, $3 \mathrm{~m} / \mathrm{s}$ (people can feel the wind.) and $7 \mathrm{~m} / \mathrm{s}$ (wind can blow dust.) while other parameters remain the same. For example, the following parameters: north wind, temperature of $25^{\circ} \mathrm{C}$, relative humidity of $50 \%$, time step for 10 minutes have yielded the results in Figure 2. And clearly the wind speed has a large effect on fire spread, as the burning area at each time range of wind speed of $7 \mathrm{~m} / \mathrm{s}$ is more than 3 times of that of $3 \mathrm{~m} / \mathrm{s}$.

In the temperature comparative experiments, the air temperature is set to $10^{\circ} \mathrm{C}$ and $30^{\circ} \mathrm{C}$ respectively while other parameters remain the same. The experimental results are shown in Figure 3. It can be seen that when the temperature is higher and the air is drier, combustibles are more likely to be ignited; when the temperature is lower and the air is colder and wetter, combustibles are not easily ignited.

As a key parameter in the process of fire simulation, fire-resistant elements also have a huge impact on fire spread, especially those in the natural environment, such as rivers, lakes and roads. In this paper, experiments are conducted separately for natural fire-resistant elements (roads and lakes). The experimental results are shown in Figure 4. It can be seen that roads and lakes do have a certain blocking effect on further spread of the fire.

After considering each individual parameter separately, we also conducted dynamic experiments of the model parameters. The dynamic experiments of the parameter are mainly targeted at the phenomenon that the environmental variables change dynamically during the fire simulation, especially wind direction, wind speed and temperature, which are in a state of uncertainty and change in almost real time. As shown in Figure 5, it is obvious that when the wind direction converted from north to northwest after 10 minutes, the main direction of fire burning had also changed to northwest. It can also be seen that when only the wind direction changed, the burning area was not much different from that under stable conditions. 

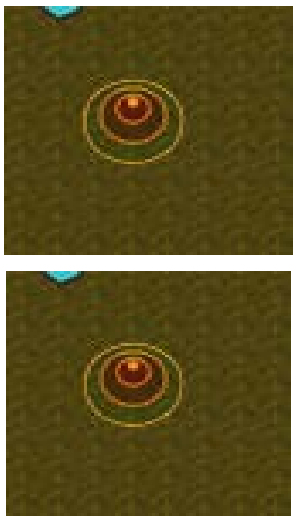

Fig. 1. The impact of wind directions on fire spread
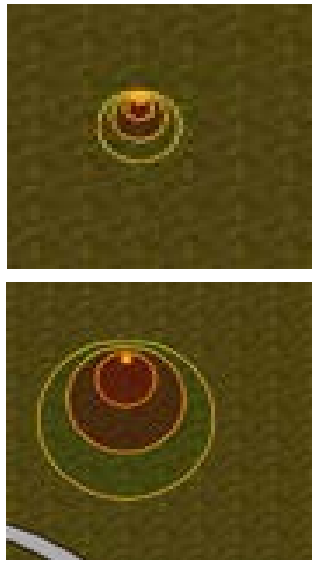

Fig. 3. The impact of temperature on fire spread

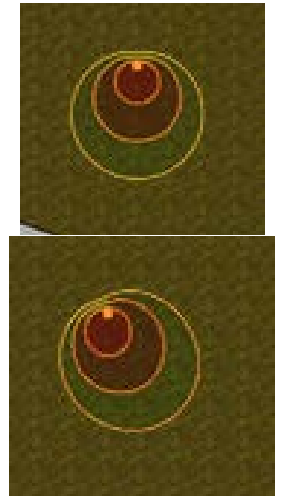

Fig. 5. The impact of dynamic parameters on fire spread

The final experiment is to study the fire spread under the combined influences of dynamic parameters and the fire-resistant factor in the model. The total duration of the
Fig. 2. The impact of wind speed on fire spread
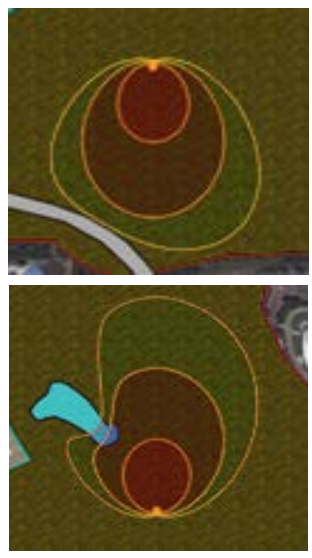

Fig. 4. The impact of fire-resistant elements on fire spread

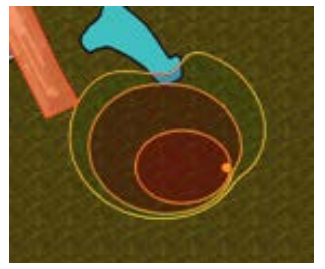

Fig. 6. The impact of integrated parameters on fire spread
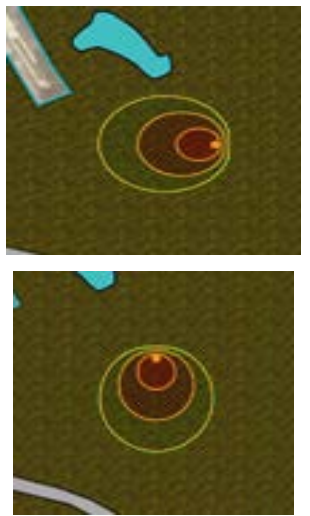
simulation is set to 30 minutes with 10 -minute intervals. We divided 30 minutes into three equal time periods, and the results are shown in Figure 6. It can be found from the figure that the wind direction changes with time and the main direction of fire changed from east to southeast and then to south. In addition, the lake, one of the natural fire-resistant factors, can significantly curb the fire spread and a building near the forest has already been ignited. All parameters in the comparison experiment are shown in Table 2, which indicates that the fire spreading process is influenced by a variety of factors and is relatively dynamic and random. Since wind speed and temperature have exerted greater impact on the fire spreading area, the fire department should enhance monitoring of fire potentials under such climatic conditions as high temperature or strong wind.

Table 2. The results of multi-parameter comparative experiment of fire simulation

\begin{tabular}{ccccc}
\hline \multirow{2}{*}{ parameter } & \multirow{2}{*}{ value } & \multicolumn{3}{c}{ Fire spread area (square meter) } \\
\cline { 2 - 5 } & & 10 minutes & 20 minutes & 30 minutes \\
\hline \multirow{2}{*}{ Wind direction } & East wind & 2208.79 & 8835.2 & 19879.2 \\
\cline { 2 - 4 } & North wind & 2149.92 & 8599.71 & 19349.36 \\
\hline \multirow{2}{*}{ Wind speed } & $4 m / s$ & 926.55 & 3706.16 & 8338.88 \\
\cline { 2 - 4 } & $8 m / s$ & 2965.18 & 11860.73 & 26686.63 \\
\hline \multirow{2}{*}{ temperature } & $10^{\circ} \mathrm{C}$ & 354.10 & 1416.35 & 3186.79 \\
\cline { 2 - 4 } Fire-resistant factors & $30^{\circ} \mathrm{C}$ & 3085.89 & 12343.51 & 27772.91 \\
\cline { 2 - 4 } & Roads & 8247.33 & 32989.35 & 57926.63 \\
\hline \multirow{2}{*}{$\begin{array}{c}\text { Dynamics of the } \\
\text { parameters }\end{array}$} & Lakes & 9226.36 & 34455.53 & 73021.5 \\
\cline { 2 - 4 } & Stable & 2149.92 & 8599.71 & 19349.36 \\
\hline Integrated factors & dynamic & 2149.93 & 8373.17 & 18914.29 \\
\hline
\end{tabular}

The above research is intended to analyze the influences of changed parameters on the simulation results of the fire models and then provides decision support for the government in fire emergency rescue. The experiments also prove that the integrated fire simulation system has strong robustness and that the hybrid fire spread model based on Cellular Automata is feasible in practical application. The model can be compatible with the existing fire emergency system for more accurate fire alarm.

\section{Conclusion}

This paper proposes a fire warning model based on Cellular Automata, which can quickly and accurately simulate the fire spread process under mixed forest and building scenarios and provide timely and reliable decision support for the firefighting task. The model solves the problem of imbalance between the speed and accuracy of fire stimulation in a single scenario and manages to simulate the fire process under complex structures. Being adaptable and expansible, the method proposed in this paper can support the simulation of fire scenarios with a mixture of various factors and achieve an approximate real fire simulation effect. Further researches will be carried out towards simulating the fire spread process under large-scale and complex structure scenarios, so as to realize the whole process more quickly and effectively. 


\section{Acknowledgments}

This work was supported by Science and Technology Project of State Grid Corporation of China (Contract No:SGSW0000AQJS2000094).

\section{References}

[1] Kumar P V, Challa A, Ashok J and Narayanan G L 2015 Int. Conf. on Microwave, Optical and Communication Engineering (Bhubaneswar) pp 72-75

[2] Ying W 2016 Reborn of the moonlight city: the fire accident of shangrila county in Yunnan province in 2014 DISASTER REDUCTION IN CHINA 24-27

[3] Cheng H and Hadjisophocleous G V 2011 Dynamic modeling of fire spread in building Fire Safety Journal 46 211-224

[4] Zhao S 2011 Simulation of mass fire-spread in urban densely built areas based on irregular coarse cellular automata Fire Technology 47 721-749 